TECHNO

Vol.19, No.2, Oktober 2018, Hal. 71 78

P-ISSN: 1410-8607, E-ISSN: 2579-9096

\title{
Turbin Air Tesla dengan Variasi Diameter Lubang Keluaran
}

\author{
TESLA WATER TURBINE WITH OUTLET HOLE DIAMETER VARIATIONS
}

M. Mirmanto, Arif Mulyanto, Buyung Anugerah

Jurusan Teknik Mesin, Fakultas Teknik, Universitas Mataram, Mataram, NTB

\section{Informasi Makalah}

Dikirim, 21 Agustus 2018

Direvisi, 05 Oktober 2018

Diterima, 07 Oktober , 2018

\section{Kata Kunci:}

Daya

Diameter lubang

Efisiensi

Torsi

Turbin

\begin{abstract}
INTISARI
Paper ini menyajikan hasil pengujian turbin air menggunakan prinsip turbin Tesla. Diameter lubang keluaran, yang berjumlah 4, divariasikan yaitu 10 $\mathrm{mm}, 15 \mathrm{~mm}$ dan $20 \mathrm{~mm}$. Sedangkan diameter piringan turbin yang digunakan sebesar $120 \mathrm{~mm}$ dengan tebal piringan $2 \mathrm{~mm}$, jumlah piringan 3 dan jarak antar piringan $2 \mathrm{~mm}$ serta terbuat dari CD bekas. Turbin diuji dengan head setinggi 5,2 m. Tujuan dari penelitian ini adalah untuk mengetahui pengaruh variasi besar diameter lubang pada piringan turbin terhadap unjuk kerjanya. Hasil penelitian menunjukan bahwa torsi terbesar dihasilkan oleh turbin dengan diameter lubang $20 \mathrm{~mm}$ yaitu 0,07 Nm pada putaran poros $203 \mathrm{rpm}$ dan torsi terkecil didapat oleh turbin dengan diameter lubang $10 \mathrm{~mm}$ yaitu 0,01 Nm pada putaran $702 \mathrm{rpm}$. Daya maksimum dihasilkan sebesar 2,03 W pada putaran poros $403 \mathrm{rpm}$ dan diameter lubang $20 \mathrm{~mm}$. Daya minimum dihasilkan oleh turbin dengan diameter lubang $10 \mathrm{~mm}$ adalah $0,404 \mathrm{~W}$ pada putaran poros $702 \mathrm{rpm}$. Efisiensi terbesar dihasilkan oleh turbin dengan diameter lubang $20 \mathrm{~mm}$ yaitu sebesar 6,57\% dan efisiensi terkecil didapat pada turbin dengan diameter lubang $10 \mathrm{~mm}$ yaitu $1,3 \%$.
\end{abstract}

\section{Keyword:}

Power

Hole diameter

Efficency

Torsion

Turbine

\begin{abstract}
This paper presents the results of water turbine test using Tesla turbine principle. The outlet holes, which amounts of 4, were varied, i.e. $10 \mathrm{~mm}, 15$ $\mathrm{mm}$ and $20 \mathrm{~mm}$. The diameter of the turbine disks used in this study was 120 $\mathrm{mm}$ with a thickness of $2 \mathrm{~mm}$, the plate number of 3 , and the gap between the disks of $2 \mathrm{~mm}$. The disks were made of used CD. The turbine was examined with a head of $5.2 \mathrm{~m}$. The purpose of this current study is to know the effect of the hole diameter of the turbine disks on the turbine performance. The results show that the biggest torque of $0.075 \mathrm{Nm}$ was obtained using the turbine with a hole diameter of $20 \mathrm{~mm}$ at the rotation of $203 \mathrm{rpm}$, and the smallest torque of $0.01 \mathrm{Nm}$ was attained using the turbine with a hole diameter of $10 \mathrm{~mm}$ at the rotation of $702 \mathrm{rpm}$. The maximum power of the turbine is about $2.03 \mathrm{~W}$ at the rotation of $403 \mathrm{rpm}$ and a hole diameter of $20 \mathrm{~mm}$. The minimum power of the turbine is $0.404 \mathrm{~W}$ obtained using the turbine with the hole diameter of $10 \mathrm{~mm}$ at the rotation of $702 \mathrm{rpm}$. The biggest efficiency is $6.57 \%$ obtained using the turbine with a hole diameter of $20 \mathrm{~mm}$ and the smallest efficiency is $1.3 \%$ attained using the turbine with a hole diameter of $10 \mathrm{~mm}$.
\end{abstract}

\section{Korespondensi Penulis:}

M. Mirmanto

Jurusan Teknik Mesin, Fakultas Teknik

Universitas Mataram

Jl Majapahit no. 62 Mataram, NTB, 83125, Indonesia

Email: m.mirmanto@unram.ac.id 


\section{PENDAHULUAN}

Perkembangan teknologi yang pesat meningkatkan kebutuhan energi. Sementara itu ketersediaan sumber energi yang tidak dapat diperbaharui semakin menipis. Sumber energi yang terbarukan seperti energi potensial pada air sangat memungkinkan untuk dimanfaatkan. Sembiring [1] mengatakan bahwa di Indonesia, sumber air sangatlah melimpah, tetapi untuk memanfaatkannya memerlukan alat-alat yaitu salah satunya adalah turbin air yang mampu mengubah energi potensial dan kinetik menjadi energi mekanik.

Turbin Tesla merupakan suatu mesin yang merubah energi fluida menjadi energi mekanik dengan menggunakan disk/ piringan yang disusun paralel/ berjajar pada suatu poros dengan jarak antar piringan tertentu. Penentuan besar celah sangat penting terhadap besarnya gaya putar yang bisa dihasilkan dengan melihat kondisi viskositas air.

Konsep turbin Tesla ditemukan pertama kali oleh Nikola Tesla. Turbin Tesla pertama kali dibuat pada tahun 1906 oleh Julius C. Czito, menggunakan 8 buah piringan yang berdiameter 15,2 cm dengan berat kurang dari 4,5 kg dapat membangkitkan daya sebesar $30 \mathrm{Hp}$ dengan putaran maksimum mencapai 35000 rpm. Pada tahun 1910 Czito dan Tesla membuat model yang lebih besar dengan piringan berdiameter 30,5 cm. Putarannya hanya mencapai 10000 rpm dan menghasilkan daya sebesar $100 \mathrm{Hp}$. Seperti dijelaskan oleh Rizaldi [2], pada tahun 1911 Czito dan Tesla membuat model dengan diameter piringan sebesar 24,8 cm, putarannya berkurang menjadi 9000 rpm tetapi daya yang dihasilkan malah semakin besar yakni sebesar 110 Hp.

Rizaldi [2] telah melakukan penelitian tentang rancang bangun turbin Tesla sebagai turbin air dan analisa perbandingan variasi jumlah disk dan jarak antar disk. Dalam penelitian ini bahan yang digunakan sebagai disk adalah pelat besi dengan ketebalan disk $2 \mathrm{~mm}$ dan variasi jumlah disk yang digunakan adalah 25 disk dan 19 disk dengan variasi jarak antar disk 1 dan 2 mm. Hasil yang didapatkan dari penelitian ini adalah untuk turbin Tesla dengan tebal dan jarak disk yang berbeda pada putaran $400 \mathrm{rpm}$ menghasilkan daya sebesar 7,52 W dan efisiensi 27,89\%. Sedangkan untuk turbin Tesla dengan tebal dan jarak disc yang sama pada putaran $420 \mathrm{rpm}$ menghasilkan daya sebesar $9.42 \mathrm{~W}$ dan efisiensi 30,74\%.

Borate dan Misal [3] meneliti efek permukaan lapisan penutup dan jarak antar disk terhadap kinerja turbin. Mereka menggunakan 6 disk dengan diameter disk $152 \mathrm{~mm}$ dan tebal disk $2 \mathrm{~mm}$. Permukaan lapisan penutup bervariasi dari halus sampai 500ra dan variasi jarak antar disk yang digunakan adalah 0,5 mm, 1 $\mathrm{mm}, 1,5 \mathrm{~mm}, 2 \mathrm{~mm}$ dan 2,5 mm. Mereka menyimpulkan bahwa jumlah disk, jarak antara disk dan permukaan lapisan penutup disk mempengaruhi kinerja turbin secara signifikan. Kecepatan rotor meningkat dengan jumlah disk sampai di tingkat tertentu. Hal ini dikarenakan oleh meningkatnya daerah kontak dari jet air dengan dinding dan mengarah ke peningkatan kekuatan gesek dan efek lapisan batas.

Awasthi dan Aggarwal [4] telah melakukan pembandingan kinerja turbin Tesla seacra teori dan percobaan. Mereka menggunakan jarak antara disk yang divariasikan yaitu 0,5 mm, $1 \mathrm{~mm}, 1,5 \mathrm{~mm}$ dan $2 \mathrm{~mm}$ dengan ketinggian air jatuh 12,8 $\mathrm{m}$ dan debit 0,0001368 m³. Kesimpulan yang didapat adalah (i) jarak antara disk adalah faktor penting dalam pembangunan turbin, (ii) kecepatan maksimum dicapai oleh turbin pada gap antar disk $1 \mathrm{~mm}$, putaran $1500 \mathrm{rpm}$ dan kondisi tanpa beban, (iii) percobaan dengan gap 1,5 mm dan beban lampu LED 0,75 W, 1 W, 3 W dan 6 W menghasilkan efisiensi 36,8 \%.

Choon et al. [5] telah melakukan penelitian tentang turbin Tesla dengan CFD untuk mengetahui torsi, efisiensi dan head loss turbin Tesla. Ada 2 desain turbin yang digunakan pada penelitian mereka ini. Desain pertama dengan jumlah disk 21, diameter disk 110 mm, jarak disk 0,31 mm, tekanan masuk 103896,1 $\mathrm{Pa}$, tekanan keluar 101325,01 Pa, kecepatan masuk 4,197 m/s dan kecepatan keluar 0,680 m/s. Sedangkan desain yang kedua dengan jumlah disk 13, diameter disk $140 \mathrm{~mm}$, jarak disk 0,32 mm, tekanan masuk 103985,7 Pa, tekanan keluar 101325,02 Pa, kecepatan masuk 4,19 m/s dan kecepatan keluar 0,682 m/s. Hasil dari penelitian ini adalah pada desain pertama mendapatkan torsi 0,0210 Nm dengan efisiensi 6,8 \% dan head loss 0,44 m. Sedangkan desain kedua mendapatkan torsi 0,0330 Nm dengan efisiensi 10,7 \% dan head loss 0,04 .

Jose et al. [6] melakukan studi teoritis pada permukaan lapisan penutup, jarak antara disk dan kinerja turbin Tesla. Mereka menyimpulkan bahwa jumlah disk, jarak antara disk dan permukaan disk mempengaruhi kinerja turbin Tesla secara signifikan. Untuk jarak yang lebar antara disk ini hanya berfungsi sebagai turbin impuls. Percobaan yang ada menunjukkan bahwa kerugian yang terjadi pada nozzle sangat besar dan karenanya perlu ditangani untuk meningkatkan efisiensi keseluruhan turbin Tesla. Eksperimental menunjukkan bahwa efisiensi dari disk dapat ditingkatkan sebesar 5 sampai 6\% dengan menggunakan disk alur spiral (disk kasar).

Machado et al. [7] telah melakukan penelitian tentang efisiensi turbin Tesla. Percobaan mereka menghasilkan efisiensi yang jauh lebih rendah dari perkiraan. Efisiensi teoritis Tesla untuk turbin berkisar antara 99\% sampai 40\% namun efisiensi eksperimental kira - kira antara 2,5\% dan 4,7\%. Ada sejumlah variabel yang tidak diperhitungkan saat mengukur data eksperimen dan yang dapat mempengaruhi kinerja

Techno Vol. 19, No. 2, Oktober 2018: $71-78$ 
turbin jika dimodifikasi. Beberapa variabel yang diperhitungkan yaitu resistansi bantalan (gesekan), mengingat turbin beroprasi pada putaran yang sangat tinggi melebihi $11000 \mathrm{rpm}$ selama berjalan tanpa beban, bantalan ABEC 7 dengan kecepatan operasi 14000 rpm dipilih namun tetap panas. Dari uji coba dan teori Tesla dibalik pengoperasian turbin tidak jelas bagaimana lubang keluar antar disk akan mempengauhi kinerja turbin. Delapan lubang pada jarak yang sama dari pusat disk, pada 45 derajat putaran pemisahan dan diameter 3/8 dipilih karena menyerupai desain yang digunakan oleh Tesla.

Peshlakai [8] telah membuat penelitian tentang penghambat fleksibilitas turbin Tesla: variasi fluida kerja dan kinerja turbin. Turbin Tesla terbukti menjadi penggerak utama serbaguna mampu menghasilkan tenaga dari berbagai fluida kerja. Hasil uji eksperimental menunjukkan bahwa turbin khusus ini paling sesuai untuk gas ideal atau uap, namun kinerjanya buruk sebagai turbin hidro. Kemampuan turbin ini untuk menerima uap jenuh memberikan manfaat bagi kemungkinan sistem tenaga rankine berskala kecil menjadi pilihan yang tepat untuk produksi tenaga skala perumahan. Kinerja turbin Tesla tidak dioptimalkan, namun efisiensi rotor turbin dan keluaran daya dipresentasikan untuk dua nozzle yang berbeda yang digunakan dalam pengujian. Percobaan mengkonfirmasi bahwa efisiensi turbin dapat melebihi 30\%. Sembiring [1] telah melakukan pengujian pengaruh variasi jumlah dan jarak antar disk pada rancang bangun turbin Tesla dengan kapasitas air konstan. Dalam pengujian ini bahan yang digunakan sebagai disk adalah plat besi dengan ketebalan $2 \mathrm{~mm}$ dan variasi jumlah disk yang digunakan adalah 25 dan 19 disk dengan variasi jarak antar disk 1 dan 2 mm dengan head 9,41 m. Hasil yang didapatkan adalah turbin Tesla dengan jumlah disk 25 dan variasi jarak $1 \mathrm{~mm}$ memberikan efisiensi maksimum 16,81\%, daya maksimum sebesar 17,56 W pada putaran 329 rpm dengan beban 60 N. Sedangkan turbi Tesla dengan jumlah disk 19 dan variasi jarak antar disk 2 mm memberikan efisiensi maksimum sebesar 17,89\%, daya maksimum sebesar 18,69 W, pada putaran 262,6 rpm dengan beban $80 \mathrm{~N}$. dari kedua variasi didapatkan variasi terbaik pada jumlah disk 19 dengan jarak antar disk $2 \mathrm{~mm}$.

Dari telaah literatur di atas, diperoleh gambaran bahwa secara umum disk yang digunakan terbuat dari besi, dan pengaruh diameter disk serta gap antar disk terhadap unjuk kerja turbin sangat siknifikan. Namun demikian, dari literatur di atas, belum Nampak apa pengaruh dari lubang keluaran terhadap kinerja turbin Tesla. Oleh sebab itu, penelitian ini bertujuan mengetahui pengaruh diameter lubang keluaran terhadap kinerja turbin Tesla.

\section{METODOLOGI PENELITIAN (10 PT)}

\subsection{Fasilitas dan bahan}

Alat instalasi penelitian ditunjukan pada gambar 1, sedangkan dimensi dari piringan/ disk ditunjukan pada gambar 2. Alat ini terdiri dari beberapa komponen yang ditunjukan dengan nomor. Air dialirkan dari sumur menggunakan pompa masuk ke dalam tandon (bak penampung atas) setinggi lebih dari 5,2 m. Dari tandon air dialirkan melalui turbin Tesla (seksi uji) yang letaknya kurang lebih 5,2 m dari permukaan air di dalam tandon ke bawah. Ketika air melalui turbin, maka turbin memutar dan putaran serta dayanya diukur.

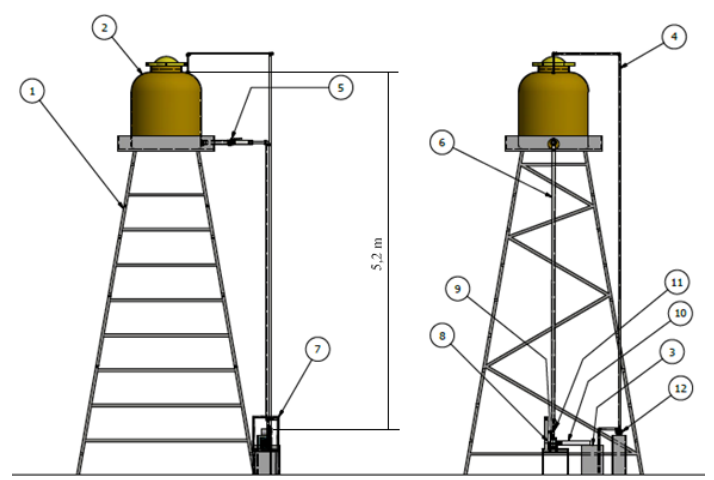

1. Tiang/Menara, 2. Penampung atas (tandon), 3. Penampung bawah, 4. Pipa instalasi pompa, 5. Katup penampung atas, 6. Pipa instalasi turbin, 7. Dinamometer, 8. Pulley, 9. Turbin Tesla, 10. Pipa keluaran air turbin, 11. Katup nozzle, 12. Pompa.

Gambar 1 Skema alat penelitian 
Putaran turbin diukur dengan menggunakan Tachometer model DT 2234C dengan rentang pengukuran 2-10000 rpm dan akurasi 0,05\%, sedangkan daya poros diukur dengan menggunakan sistem pengereman, seperti ditunjukan pada gambar 3. Cara kerja dari rem ini hampir sama dengan rem cakram atau sejenisnya, tetapi sepatu rem ini terdiri dari tali yang menyentuh sebagian keliling roda. Tali dibuat dari bahan kulit dan ujung tali yang satu dikaitkan pada spring balance, ujung yang satunya lagi diberi beban. Penyerapan daya dilakukan oleh tali karena gesekan dengan poros roda tersebut. Rem tali sangat sederhana dan mudah dibuat, tetapi hanya bisa bekerja pada putaran rendah dengan kapasitas penyerapan daya kecil. Diameter piringan yang digunakan $120 \mathrm{~mm}$ dan tebal piringan 1,2 mm serta jumlah piringan 3. Diameter lubang keluaran yang divariasikan adalah $10 \mathrm{~mm}, 15 \mathrm{~mm}$ dan $20 \mathrm{~mm}$. Bahan dari piringan pada studi ini adalah CD bekas. Piringan-piringan ini disusun berjajar dalam satu poros dengan diberi gap setebal $2 \mathrm{~mm}$. Gap atau spacer ini yang juga dibuat dari CD bekas dengan diameter $32 \mathrm{~mm}$. Jari-jari pulley, yang merupakan komponen yang direm menggunakan tali, adalah sebesar 27,5 mm. Model pengukuran gaya dengan metode pengereman juga telah dilakukan oleh Muliawan dan Yani [9].

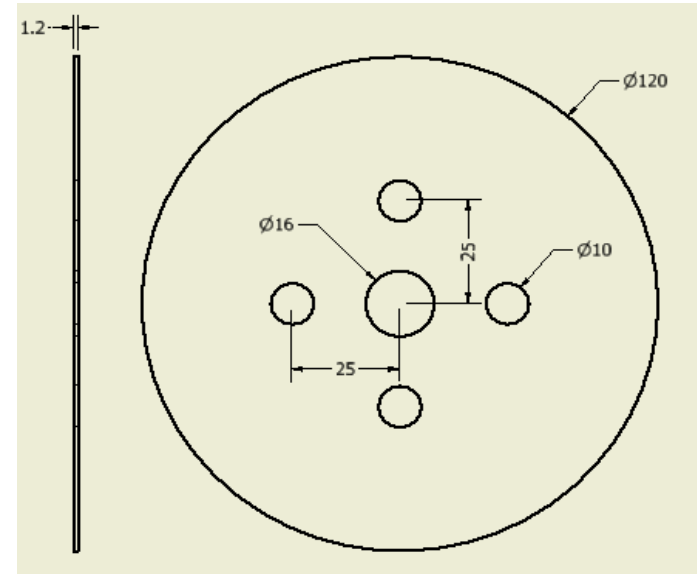

Gambar 2 Piringan turbin dengan diameter lubang keluaran $10 \mathrm{~mm}$.

\subsection{Data reduksi}

Untuk menganalisis hasil percobaan, beberapa persamaan perlu digunakan. Pada penelitian ini menggunakan dinamometer rope break untuk mengukur torsi dan alat tachometer untuk mengetahui rpm turbin. Berikut adalah persamaan untuk menghitung torsi yang dibangkitkan oleh turbin, yang mana persamaan tersebut juga digunakan oleh Awasthi and Aggarwal [4]:

$T=F R$

Dengan $F$ adalah gaya dan $R$ merupakan jari-jari poros. Pada roda turbin terdapat kecpatan tangensial, seperti yang tertulis pada Awasthi and Aggarwal [4] yaitu:

$u=\omega r$

Dimana $u$ adalah kecepatan tangensial (m/s), $\omega$ adalah kecepatan sudut (rad/s) dan $r$ adalah jari-jari piringan (m). Sementara itu, kecepatan sudut dapat diestimasi dengan persamaan seperti yang digunakan oleh Awasthi and Aggarwal [4]:

$\omega=\frac{2 \pi n}{60}$

Dengan $n$ adalah putaran turbin dalam rpm. Daya turbin, $P_{T}$, dapat dihitung menggunakan rumus yang dapat dilihat di Awasthi and Aggarwal [4]:

$$
P_{T}=\frac{2 \pi n T}{60}
$$


Dimana $T$ adalah torsi turbin (Nm), sedangkan efisiensi dihitung menggunakan rumus yang juga digunakan pada Rizaldi [2]:

$\eta=\frac{P_{T}}{\rho g h Q} \times 100 \%$

Dimana $\eta$ adalah efisensi (\%), $\rho$ adalah massa jenis $\left(\mathrm{kg} / \mathrm{m}^{3}\right), g$ adalah gravitasi bumi $\left(\mathrm{m} / \mathrm{s}^{2}\right), h$ adalah ketinggian air turun/terjun atau head (m), dan $Q$ adalah laju aliran volumetric atau debit aliran (m³/s).

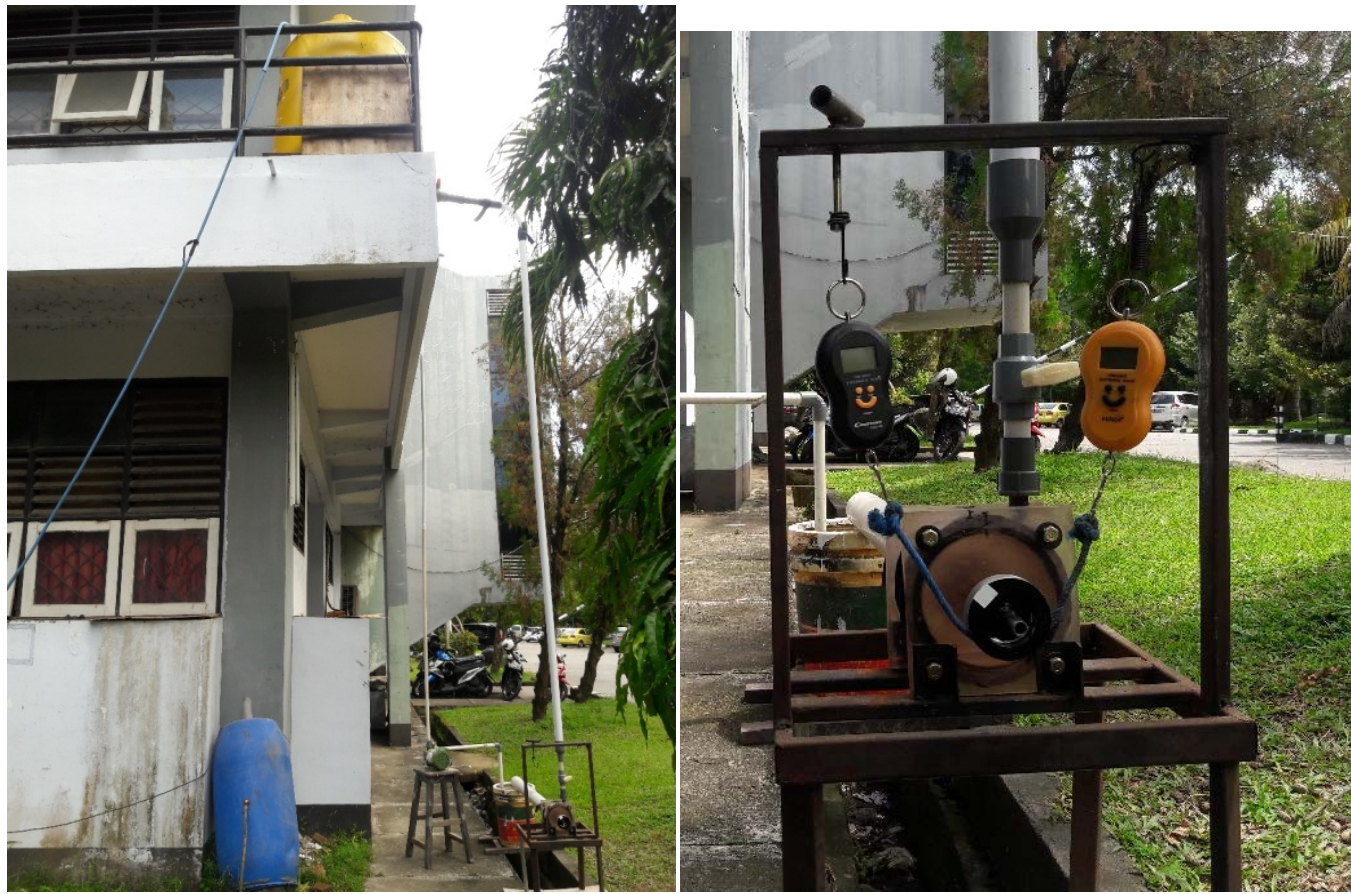

Gambar 3 Instalasi dan Dynamometer rope break

\section{HASIL DAN PEMBAHASAN}

Setelah melakukan penelitian pada turbin Tesla dengan diameter lubang keluaran $10 \mathrm{~mm}, 15 \mathrm{~mm}$, $20 \mathrm{~mm}$ dan head yang digunakan 5,2 $\mathrm{m}$, selanjutnya dilakukan pengukuran putaran poros dan gaya pada turbin. Data pengukuran yang didapat digunakan sebagai bahan perhitungan untuk menentukan torsi, daya dan efisiensi dari turbin tersebut. Data tersebut disajikan pada gambar 4.

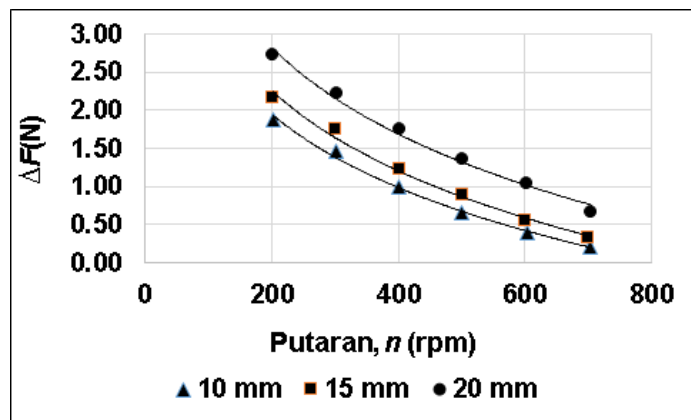

Gambar 4 Hubungan antara putaran dengan gaya resultan pada pulley pengereman 
Gambar 4 menunjukan bahwa jika putaran meningkat, maka gaya justru turun. Hal ini disebabkan ketika gaya yang diberikan pada rem tinggi, maka tentu saja poros tidak dapat berputar lebih kencang, sebab gaya gesekannya besar dan demikian pula jika sebaliknya. Namun demikian, trend yang demikian juga ditemukan oleh Muliawan dan Yani [9]. Mereka memperoleh gaya berkisar dari $3 \mathrm{~N}$ sampai dengan 9,7 N dengan putaran $10 \mathrm{rpm}$ sampai dengan $90 \mathrm{rpm}$. Gambar 4 juga menunjukan bahwa semakin besar diameter lubang keluaran, maka semakin besar gaya yang dihasilkan. Sebagai contoh pada putaran 200 rpm, untuk diameter lubang $10 \mathrm{~mm}$ lebih kecil gayanya dibandingkan dengan diameter lubang yang lebih besar. Gaya ini jika dikalikan dengan jari-jari putaran maka akan menjadi torsi turbin. Hasil perkalian antara gaya dengan jari-jari pulley ditunjukan pada gambar 5 . Tentu saja tren hubungan antara putaran dengan torsi akan sama dengan tren hubungan antara putaran dengan gaya. Oleh sebab itu, jika putaran naik, maka torsi akan turun dan sebaliknya. Torsi proporsioanal dengan gaya. Oleh sebab itu, torsi naik dengan diameter lubang yang lebih besar.

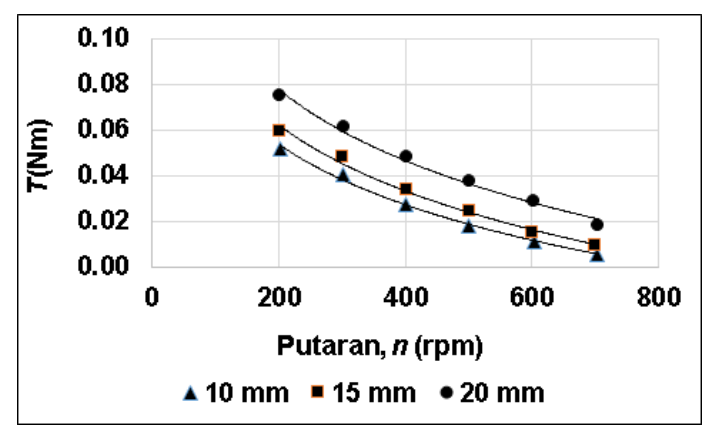

Gambar 5 Hubungan antara putaran dengan torsi

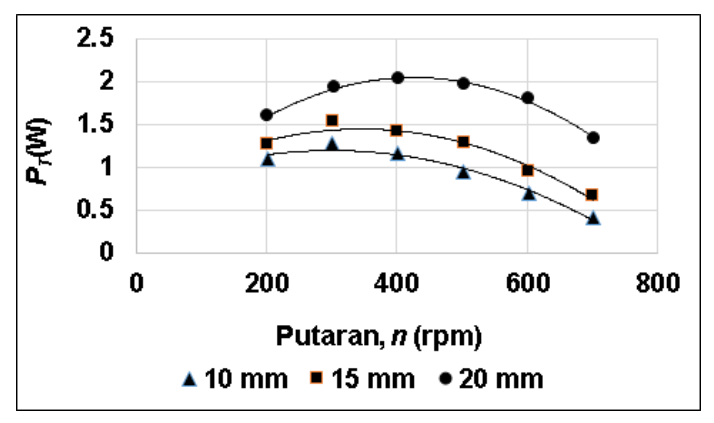

Gambar 6 Hubungan antara putaran dengan daya turbin

Variabel lainya yang dicari pada studi ini adalah daya. Daya merupakan perkalian antara torsi dengan kecepatan angulernya seperti persamaan (4). Daya hasil percobaan ditunjukan oleh gambar 6. Berbeda dengan gambar 4 dan 5, gambar 6 menunjukan bahwa meningkatnya putaran justru menaikan daya hingga mencapai puncaknya di putaran sekitar $400 \mathrm{rpm}$. Setelah lewat putaran $400 \mathrm{rpm}$, daya menurun kembali. Penyebab tren daya meningkat kemudian menurun adalah karena mengandung fungsi putaran kuadrat. Perhatikan gambar 4, gaya dipengaruhi oleh putaran atau gaya adalah fungsi putaran. Sementara itu, daya adalah torsi dikalikan dengan kecepatan anguler, yang mana kecepatan anguler adalah fungsi dari putaran. Oleh sebab itu, daya memiliki perkalian dua fungsi putaran sehingga menghasilkan grafik yang melengkung parabola terbalik dengan puncaknya berada saat putaran sekitar $400 \mathrm{rpm}$. Namun, hal yang menarik adalah semakin besar diameter lubang justru meningkatkan daya turbin. Tetapi artinya pada studi ini masih belum jelas apakah jika diameter diperbesar lagi (lebih dari $20 \mathrm{~mm}$ ) akan semakin tinggi dayanya atau justru turun. Jadi pengaruh diameter lubang terhadap daya perlu diteliti lebih lanjut misal dengan diameter lubang 25 mm, $30 \mathrm{~mm}$ dan seterusnya. Untuk studi ini, besar diameter lubang $20 \mathrm{~mm}$ adalah yang terbaik sebab menghasilkan gaya, torsi dan daya yang paling tinggi dibandingkan dengan diameter lubang yang lainya. Tetapi tren daya demikian juga pernah ditemukan oleh Muliawan dan Yani [9]. Artinya hasil penelitian ini 
tidak menympang dari jalur yang benar. Muliawan dan Yani [9] menjelaskan bahwa daya maksimum diperoleh pada putaran 50-70 rpm sedangkan pada studi ini daya maksimum didapat pada putaran sekitar 400 rpm. Hal demikian bisa saja terjadi karena berbeda kondisi dan berbeda material yang digunakan sebagai turbin. Selanjutnya adalah efisiensi turbin perlu dipresentasikan sebab menjadi salah satu variable yang menjadi tujuan pada studi ini. Hubungan efisiensi dengan putaran ditunjukan pada gambar 7 . Efisiensi dapat dihitung dengan menggunakan persamaan (5) yaitu perbandingan antara daya turbin dengan daya fluida.

Gambar 7 menunjukkan bahwa efisiensi akan semakin meningkat hingga titik maksimum pada putaran 400 rpm dan kemudian menurun, hal ini disebabkan karena pada saat putaran poros meningkat dan torsi yang didapat tidak sebanding dengan daya yang dihasilkan, sehingga mempengaruhi efisiensi turbin. Tren efisiensi juga sama dengan tren daya, sebab efisiensi diperoleh dari daya turbin dibagi dengan daya air, sementara daya air pada studi ini adalah konstan. Pada gambar 7, efisiensi tertinggi, 6,15\%, diperoleh pada turbin dengan diameter lubang $20 \mathrm{~mm}$ dan putaran 403 rpm. Pada diameter lubang $15 \mathrm{~mm}$ dan putaran 402 rpm, efisiensi maksimum yang didapat adalah 4,98 \% dan terakhir, turbin dengan diameter lubang $10 \mathrm{~mm}$ pada putaran $501 \mathrm{rpm}$ menghasilkan efisiensi 4,50\%.

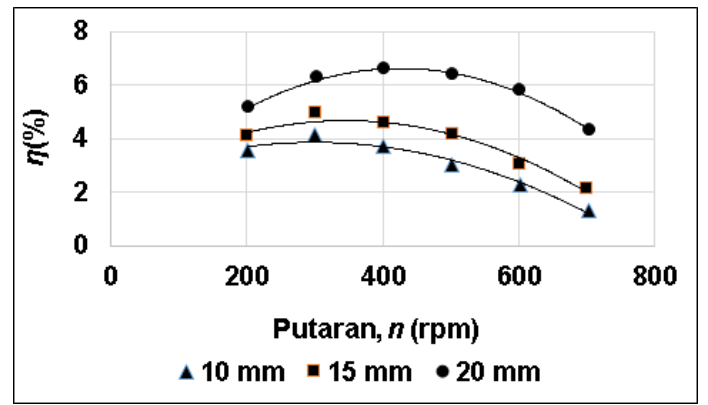

Gambar 7 Hubungan antara putaran dengan efisiensi operasional turbin

\section{KESIMPULAN}

Penelitian pengaruh diameter lubang keluaran terhadap kinerja turbin air yang menggunakan prinsip Tesla telah dilakukan dan telah ditelaah pada bagian hasil dan pembahasan. Hasil percobaan dan analisis memberikan kesimpulan bahwa gaya yang dihasilkan oleh turbin dipengaruhi oleh putaran. Semakin tinggi putaran semakin rendah gaya yang dihasikan. Turbin dengan diameter lubang $20 \mathrm{~mm}$ menghasilkan gaya yang lebih besar dibandingkan dengan yang lainya. Torsi turbin juga memiliki tren yang sama dengan gaya yaitu menurun dengan meningkatnya putaran. Semakin besar diameter lubang semakin besar torsi yang dihasilkan. Daya dan efisiensi meningkat dengan meningkatnya putaran kemudian mencapai puncaknya yaitu pada putaran 400 rpm, dan selanjutnya daya dan efisiensi menurun dengan meningkatnya putaran.

\section{UCAPAN TERIMAKASIH}

Penulis mengucapkan banyak terimakasih kepada Jurusan Teknik Mesin, Fakultas Teknik, Universitas Mataram, atas fasilitas yang digunakan dan berterimakasih kepada semua pihak yang membantu baik dalam melakukan percobaan maupun dalam menyusun paper ini.

\section{DAFTAR PUSTAKA}

[1] Y.M. Sembiring, "Pengujian Pengaruh Variasi Jumlah dan Jarak Antar Disk pada Rancang Bangun Turbin Tesla dengan Kapasitas Air Konstan, " Skripsi, Departemen Teknik Mesin, Fakultas Teknik, Universitas Sumatera Utara, Medan, 2015.

[2] D. Rizaldi, "Rancang Bangun Turbin Tesla Sebagai Turbin Air dan Analisa Perbandingan Variasi Jumlah Disk dan Jarak Antar Disk, " Skripsi, Departemen Teknik Mesin, Fakultas Teknik, Universitas Sumatera Utara, Medan, 2015.

[3] H.P. Borate dan N.D. Misal, "An Effect of Surface Finish and Spacing Between Discs on The Performance of Disc Turbine, " Int. J. Applied Research In Mechanical Engineering (IJARME), vol. 2(1), pp. 25-30, 2012.

[4] K. Awasthi dan A. Aggarwal, "Experimental investigation of Tesla turbine and its underlying theory, " Int. J. Engineering Trends and Technology (IJETT), vol. 13(2), pp. 98-100, 2014.

[5] T.W. Choon, et al., "Optimization Of Tesla Turbine Using Computational Fluid Dynamics Approach, " IEEE Symposium On Industrial Electronics And Applications (ISIEA2011), Langkawi, Malaysia, 2010.

[6] R. Jose, et al., "A Theoretical Study on Surface Finish, Spacing between 
Discs and Performance of Tesla Turbine," Int. Advanced Research Journal in Science, Engineering and Technology, vol. 3(3), pp. 235-240, 2016.

[7] A. Machado, et al., "Tesla Tubine Efficiency, " Fluid Mechanics, Mechanical Engineering Deparment, School of Engineering, Universidad del Turabo, Gurabo, PR 00778-3030, 2014.

[8] A. Peshlakai, "Challenging the Versatility of the Tesla Turbine: Working Fluid Variations and Turbine Performance, " Arizona State University, 2012.

[9] A. Muliawan dan A. Yani, "Analisis Daya dan Efisiensi Turbin Air Kinetis Akibat Perubahan Putaran Runner, " Journal of Sainstek, vol. 8(1), pp. 1-9, 2016. 